\title{
The Role Of Metastasectomy In Patients With Renal Cell Carcinoma With Sarcomatoid Dedifferentiation: A Matched Controlled Analysis
}

\author{
Arun Z. Thomas ${ }^{\mathrm{a}}$, Mehrad Adibi ${ }^{\mathrm{a}}$, Rebecca S. Slack ${ }^{\mathrm{b}}$, Leonardo D. Borregales ${ }^{\mathrm{a}}$, Megan M. \\ Merrilla $^{a}$, Pheroze Tambolic, Kanishka Sircar ${ }^{c}$, Eric Jonasch ${ }^{d}$, Nizar M. Tannir ${ }^{d}$, Surena F. \\ Matin $^{a}$, Christopher G. Wood ${ }^{\mathrm{a}}$, and Jose A. Karam ${ }^{\mathrm{a},{ }^{*}}$ \\ aDepartment of Urology, The University of Texas MD Anderson Cancer Center, Houston, Texas \\ ${ }^{b}$ Department of Biostatistics, The University of Texas MD Anderson Cancer Center, Houston, \\ Texas \\ 'Department of Pathology, The University of Texas MD Anderson Cancer Center, Houston, Texas \\ ${ }^{\mathrm{d} D e p a r t m e n t}$ of Genitourinary Medical Oncology, The University of Texas MD Anderson Cancer \\ Center, Houston, Texas
}

\section{Abstract}

\begin{abstract}
Purpose-Management of metastatic sRCC remains a therapeutic challenge with no standard treatment strategies. Our objective was to evaluate whether metastasectomy has any survival benefit in patients with metastatic sRCC treated with radical nephrectomy (RN).
\end{abstract}

\begin{abstract}
Patients and Methods-From an institutional database of 273 patients with sRCC treated with nephrectomy, we matched 80 patients with synchronous and asynchronous metastasis for age, ECOG performance status, histology and lymph node (LN) status. Matched pairs were then retained only if patients who did not undergo metastasectomy were comparably alive at the time of metastasectomy in matched surgical patients to reduce the bias in survival outcomes. Overall survival (OS) from nephrectomy was studied using univariable and multivariable proportional hazards regression.
\end{abstract}

Results-Median OS was 8.3 months (95\%CI:6.5-10.5 months) and 18.5 months (95\%CI:11.542.9 months) for patients with synchronous and asynchronous metastases, respectively. OS for patients undergoing metastasectomy for synchronous metastasis compared to non-surgical patients was 8.4 and 8.0 months ( $\mathrm{p}=0.35$ ), respectively. Similarly, OS for patients with asynchronous metastases undergoing metastasectomy compared to non-surgical group was 36.2 and 13.7 months $(\mathrm{p}=0.29)$, respectively. On multivariable analysis, positive $\mathrm{LN}$ at nephrectomy was associated with

\footnotetext{
"Corresponding Author: Jose A. Karam, MD, FACS, The University of Texas MD Anderson Cancer Center, Department of Urology, 1515 Holcombe Blvd, Unit 1373, Houston, TX 77030, Phone: 713-792-3250, Fax: 713-794-4824, JAKaram@ @mdanderson.org. Publisher's Disclaimer: This is a PDF file of an unedited manuscript that has been accepted for publication. As a service to our customers we are providing this early version of the manuscript. The manuscript will undergo copyediting, typesetting, and review of the resulting proof before it is published in its final citable form. Please note that during the production process errors may be discovered which could affect the content, and all legal disclaimers that apply to the journal pertain.

Conflict of interest: Jose A. Karam has served as a one-time consultant to Pfizer in 2013. Christopher G. Wood has received research funding from Pfizer and served as a consultant and on its advisory board. None of these are relevant to the current manuscript.
} 
increased risk of death in both synchronous and asynchronous patients subgroups;

$(\mathrm{HR}=2.1,95 \% \mathrm{CI}: 1.1,4.0, \mathrm{p}=0.03)$ and $(\mathrm{HR}=3.3,95 \% \mathrm{CI}: 1.2,9.2, \mathrm{p}=0.02)$, respectively.

Conclusions-In the current study, there was no clear evidence of benefit for patients with sRCC undergoing metastasectomy after nephrectomy. Particularly, the group of patients with pathological LN positive disease at nephrectomy has a considerably worse survival.

\section{Keywords}

metastasectomy; sarcomatoid renal cell carcinoma; metastatic renal cell carcinoma

\section{INTRODUCTION}

Approximately $30 \%$ of patients with RCC have metastatic disease at presentation, and up to $40 \%$ of patient undergoing radical nephrectomy $(\mathrm{RN})$ for localized/locally advanced disease will ultimately develop metastatic disease ${ }^{1-3}$. Patients with metastatic RCC have a poor 5year survival rate of $\left\langle 20 \%{ }^{1}\right.$. Over the last decade, systemic management of metastatic RCC has significantly changed with increased understanding of the molecular biology of RCC. Agents that target vascular endothelial growth factor (VEGF) and mammalian target of rapamycin (mTOR) pathways have revolutionized the treatment of advanced RCC. However, complete response to systemic therapy alone is extremely rare and surgical resection of metastatic deposits is still valuable in well-selected patients ${ }^{4}$. Retrospective studies suggest that patients who undergo complete resection of isolated metastases tend to have better outcomes with 5-year survival rates between $35-65 \%{ }^{3,5-10}$. Favorable subgroups include patients with solitary metastases, disease free intervals after nephrectomy $>1$ year, complete resection of metastases and younger patients ${ }^{11,12}$. However, histopathologic factors have yet to be studied in predicting outcomes of patients undergoing metastasectomy.

Renal cell carcinoma with sarcomatoid dedifferentiation (sRCC) is rare variant of RCC that accounts for 1-8\% of all RCCs and can be observed across all RCC histologic subtypes. Histologically, it consists of pleomorphic spindle cells and/or malignant-appearing giant cells interposed with a carcinoma component ${ }^{13}, 14$. sRC is an aggressive tumor associated with a poor clinical course with a median survival of less than one year ${ }^{15-18}$. Conventional cytotoxic chemotherapy and IFN/IL-2 immunotherapy only result in minimal to moderate responses and survival benefit ${ }^{15}, 19$. In addition, recent reports have shown that a higher percentage of sarcomatoid component in sRCC is correlated with worse response to targeted therapy ${ }^{19,20}$. Despite recent advances in our understanding of the biology of advanced RCC, the management of metastatic sRCC continues to remain a therapeutic challenge with no standard treatment strategies. In this study, our objective was to evaluate if metastasectomy offers any survival benefit in patients with metastatic sRCC already treated with nephrectomy.

\section{PATIENTS AND METHODS}

The University of Texas MD Anderson Cancer Center institutional review board approved the current study. From 1986 to 2011, we identified 273 patients who have had nephrectomy and were diagnosed with SRCC. Patients with RCC and sarcomatoid features treated with 
nephrectomy were included in the main database. Patients diagnosed with sRCC subsequent to nephrectomy (i.e. at time of metastasectomy), with no metastatic disease, with sarcomatoid percentage of $100 \%$, in unreported clinical trials, with history of other metastatic malignancy, or with incomplete follow-up information were excluded from this study (Figure 1).

All patients in the metastasectomy groups underwent complete resection of the index organ(s) with no evidence of macroscopic disease after surgical resection. We defined synchronous metastatic disease as the presence of metastatic disease at the time of initial presentation and nephrectomy; and asynchronous disease as new metastatic disease after nephrectomy (in the absence of metastatic disease at initial diagnosis of RCC). The location of metastases was classified as lung, bone, brain, viscera and other.

Clinicopathological features recorded included patient age, gender, race, Eastern Cooperative Oncology Group (ECOG) performance status, Charlson Comorbidity Index, tumor pathology, regional lymph node (LN) involvement at time of nephrectomy, presence or absence of metastatic disease at time of nephrectomy and survival outcomes. Staging was assigned using the AJCC 2010 classification $^{21}$.

All patients underwent a metastatic evaluation including Chest X-Ray or CT Chest, and CT or MRI abdomen and pelvis prior to original nephrectomy and/or metastasectomy. Bone scan and MRI brain were obtained as clinically indicated. A regional retroperitoneal LN dissection was performed at the discretion of the operating surgeon at the time of nephrectomy. In the synchronous and asynchronous metastasectomy subgroups, surgical resection was performed primarily for sites of disease amenable to complete resection. Adjuvant and/or salvage systemic therapy for synchronous metastasis or progression to metastasis after nephrectomy (asynchronous) were administered under the discretion of the treating physician. Surveillance after surgical resection typically consisted of computerized tomography (CT) of the chest, and CT or MRI of the abdomen and pelvis at regular intervals every 3-6 months after nephrectomy and/or metastasectomy.

\section{Statistical Methods}

Patients were matched in metastasectomy/non-metastasectomy pairs for ECOG performance status, age group ( $55 \mathrm{vs}>55$ years), histology, and pathological stage and nodal status at $\mathrm{RN}$ for both synchronous and asynchronous metastases groups. Matching, balance checking, and Q-Q plots of the empirical distributions were performed using the MatchIt package ${ }^{22,23}$ in R 3.1.1 [The R Foundation for Statistical Computing]. Furthermore, to control for patients not receiving metastasectomy due to not living long enough to be able to undergo a metastasectomy, each matched pair was checked to confirm that the patient without metastasectomy lived at least until the time of metastasectomy for his/her matching metastasectomy patient. The matching algorithm was run 5 times, and the run that retained the most pairs in the end was used for analysis.

Clinical and metastasectomy characteristics were tabulated for the overall cohort and for patients with and without metastasectomy by metastatic status (synchronous or asynchronous). Overall survival (OS) was defined as the number of months from 
nephrectomy to death or last contact if still alive. Patients still alive or lost to follow-up at the close of data collection were censored on the date of last contact. OS was examined in both univariable and multivariable models for pathological tumor stage and lymph node involvement at nephrectomy, clear cell histology, metastasectomy, ECOG performance status, and age using proportional hazards regression separately based on metastatic disease status at nephrectomy. Kaplan-Meier curves are presented for characteristics that remained significantly associated with survival in the multivariate models. Analyses were carried out in SAS 9.3 (SAS Institute, Cary, NC) and plots were produced in Stata 13 (StatCorp, LP, College Station, TX).

\section{RESULTS}

\section{Baseline Clinical and Pathological Characteristics}

A total of 273 patients who underwent nephrectomy were identified as having histological sRCC from 1986 to 2011. Figure 1 illustrates the elimination process from the full cohort of 273 patients to the matched cohort of 80 patients. Table 1 shows the clinicopathological characteristics of our matched subgroup of metastatic sRCC patients receiving nephrectomy by disease status at nephrectomy. In patients with synchronous metastases, those with <25\% sarcomatoid component were more likely to undergo a metastasectomy $(p=0.02)$. In the asynchronous group, patients not receiving systemic therapy were more likely to undergo a metastasectomy $(\mathrm{p}=0.02)$.

\section{Location of Metastases/Metastasectomy}

Table 2 shows that the locations of synchronous metastases at diagnosis were comparable in the metastasectomy and non- metastasectomy groups. In the synchronous subgroup, patients with bone metastases tended to have higher rates of metastasectomy $(p=0.052)$ than the nonmetastasectomy group. Table 3 similarly shows location of asynchronous metastases. All 5 patients with brain metastases had a metastasectomy $(100 \%$ vs $0 \%, \mathrm{p}=0.01)$.

Table 4 shows that the most common sites for metastasectomy among patients with synchronous metastases were bone (57\%) and brain (30\%). For patients with asynchronous metastases, the most common site was brain (50\%). Two patients with synchronous metastases had 2 or more sites removed during the first metastasectomy. Overall, patients underwent 1 to 4 separate metastasectomies with $63 \%$ and $50 \%$ of patients having only 1 metastasectomy with synchronous and asynchronous metastases, respectively.

\section{Survival Outcomes}

Figure 2 displays the OS for the full cohort of patients by metastatic status. The median OS was 8.3 months (95\%CI:6.5-10.5 months) and 18.5 months (95\%CI:11.5-42.9 months) for patients with synchronous and asynchronous metastasis, respectively. Table 5 shows the subgroup OS comparisons by metastatic status. Among patients with synchronous metastases, no patient factors were associated with survival on univariable analyses. On multivariable analysis, patients with positive LNs have double the risk of death compared to LN negative patients (HR 2.1[95\%CI:1.1-4.0],p=0.03). For patients with asynchronous metastasis, only LN status was significantly associated with survival on univariable analysis. 
On multivariable analysis, patients with positive LNs had a 3.3-fold risk of death compared to $\mathrm{LN}$ negative patients (HR=3.3[95\%CI:1.2-9.2],p=0.03). Hence for both synchronous and asynchronous groups, when accounting for all factors together, LN status was the only factor significantly associated with survival. Figures $3 \mathrm{~A}$ and $3 \mathrm{~B}$ present the overall survival curves by LN status for patients with synchronous and asynchronous metastasis, respectively. Figures $4 \mathrm{~A}$ and $4 \mathrm{~B}$ present the overall survival curves by metastasectomy status. In the synchronous group, median OS in metastasectomy patients was 8.4 months (95\%CI:6.414.7) and 8.0 months (95\%CI:5.8-10.5) in non-metastasectomy patients ( $\mathrm{p}=0.35)$. Similarly, in the asynchronous group, median OS in the metastasectomy group was 36.2 months (95\%CI:7.6-Not Reached) and 13.7 months (95\%CI:8.8-41.6) in the non-metastasectomy group $(\mathrm{p}=0.29)$.

\section{DISCUSSION}

Studies examining the outcomes of surgical resection for both solitary and multiple RCC metastases consistently report a survival benefit of complete metastasectomy in carefully selected patients ${ }^{5,8,9,24-27}$. However, the question of whether this survival advantage is an actual consequence of surgical extirpation or rather differences that exist in tumor biology and biased patient selection still remains unanswered. Evidence from retrospective studies suggests that a proportion of patients clearly benefit from metastasectomy, whereas others rapidly succumb to disease progression even with aggressive surgical therapy.

Metastatic sRCC confers poor prognosis and a dismal clinical course with a median OS of 4-10 months from time of diagnosis ${ }^{14,15,19,28}$. Complete responses to cytotoxic chemotherapy, IFN/IL-2 immunotherapy or targeted therapy are extremely rare and have yet to demonstrate clinically meaningful response rates and survival benefit ${ }^{16,17,28}$.

We present the first study to examine the role of metastasectomy in patients with sRCC. In addition, this is the first study in RCC to examine the role of metastasectomy in a matched cohort analysis. In our cohort of patients with SRCC who already underwent nephrectomy, we show that there is no statistically significant improvement in OS in patients who undergo metastasectomy in the presence of either synchronous or asynchronous metastasis, when matched with patients who did not undergo metastasectomy. Furthermore, patients with sRCC and positive $\mathrm{LN}$ at RN have a 2.1-3.3 increased risk of death in comparison to patients with negative LNs after metastasectomy highlighting a subgroup of patients that fares particularly worse even with aggressive surgical resection.

Review of the literature concerning metastasectomy for SRCC is extremely limited. A study by Park et al. assessed outcome in 37 patients with RCC undergoing cytoreductive nephrectomy ${ }^{28}$. Overall, patients had a dismal course with median OS of 5.9 months and neither cytoreductive nephrectomy, metastasectomy or any type of systemic therapy had an effect on survival. The majority of patients (73\%) had synchronous metastases at time of diagnosis and only 2 patients underwent metastasectomy after cytoreductive nephrectomy. Likewise, only 2 out of 10 patients who had recurrent disease after nephrectomy underwent metastasectomy. Even though patients had no significant improvement in overall survival, 
the very low number of patients undergoing metastasectomy in the surgical group limited the study's ability to assess the true value of metastasectomy in $\mathrm{sRCC}^{28}$.

In one of the largest studies to examine outcomes after complete metastasectomy, Alt and colleagues ${ }^{8}$ observed that patients who underwent complete resection of all metastases experienced a significant advantage in CSS compared to patients who did not (4.8 years versus 1.3 years respectively). The authors also noted that complete surgical resection was associated with a survival benefit regardless of whether metastases were restricted to the lung only and whether multiple metastases existed. Only patients who presented initially with metastatic RCC at the time of nephrectomy with multiple synchronous metastases did not have a survival benefit from resection ${ }^{8}$. In their study, survival was calculated from the first diagnosis of metastasis to either death or last follow-up and did not account for pathological tumor characteristics (including LN status, and presence or absence of sarcomatoid elements) in patients selected for metastasectomy. Furthermore, the authors did not account for the fact that patients with more aggressive cancers would not survive long enough to be considered surgical candidates for metastasectomy, limiting the evaluation of the true survival benefit of metastasectomy.

Similarly, a recent systematic review for local treatments for RCC metastasis identified 8 studies that assessed metastases to various organ sites and examined the outcome of complete versus incomplete metastasectomy or no metastasectomy in patients with metastatic RCC. Median CSS with complete metastasectomy was 40.8 months versus 14.8 months for no metastasectomy or incomplete metastasectomy, favoring complete metastasectomy in all 8 studies ${ }^{24}$.

Even though the majority of retrospective studies show a survival advantage of metastasectomy in selected patients $8,16,17,24,29,30$, the true effect of metastasectomy on survival is harder to decipher. Arguably, patients with more aggressive tumors and/or poor performance status who died quickly did not have the chance to undergo a metastasectomy, or to benefit from metastasectomy, if one was performed. Patients with oligometastatic disease and long metachronous disease intervals tend to be selected as surgical candidates for metastasectomy compared to patients with more aggressive disease and poor performance status who do not live long enough to be considered for metastasectomy. Hence, analyses comparing survival among patients with and without metastasectomy are inherently biased towards an advantage for metastasectomy. On the other hand, it is quite unusual for a young patient, with long disease-free interval, good performance status, and oligometastatic disease not to be considered for metastasectomy.

Our study is novel in that surgical patients and non-surgical patients with synchronous and asynchronous metastatic sRCC were matched for age, performance status, histology, and LN status. More importantly, outcome of patients in the metastasectomy groups were matched to patients in the non-surgical groups only if the non-surgical patient lived at least as long as until the time of metastasectomy of the patient's matched pair in the surgical group reducing the 'lead time bias' of metastasectomy candidates. In addition, this is the first study to specifically investigate the role of metastasectomy in patients with sRCC. 
The present study has limitations due to its retrospective nature and long study time period, during which surgical and systemic treatment strategies have changed. However, chemotherapy, IFN/IL-2 immunotherapy and targeted therapies have yet to show marked survival benefit in patients with sRCC, making this limitation less important. The study sample size was small, mainly due to the performance of matched analysis, as patients without a match were not included. However, we believe it is more appropriate to have a matched cohort, albeit smaller, in order to minimize the bias in the study, rather than including a larger, unmatched cohort.

\section{CONCLUSIONS}

This is the first study on metastasectomy in RCC to perform a matched cohort analysis in patients with RCC in general, and in sRCC in particular. Pathological LN involvement at nephrectomy confers a much worse prognosis in patients that undergo metastasectomy for sRCC. Metastasectomy should still be carefully considered in this patient population if clinically indicated, especially for palliative purposes. Although metastasectomy showed a trend towards improved survival in patients with metachronous metastases, metastasectomy does not appear to provide a statistically significant survival benefit in patients with sRCC presenting with either synchronous or asynchronous metastasis at time of nephrectomy. A randomized trial would answer this question more appropriately, however such a trial is unlikely to be performed given the rarity and aggressiveness of this disease. Larger multiinstitutional studies are therefore needed to confirm our results.

\section{Acknowledgments}

Funding: The Biostatistics Resource Group is supported by the NIH/NCI under award number P30CA016672.

\section{REFERENCES}

1. Flanigan RC. Cytoreductive nephrectomy in metastatic renal cancer. Curr Urol Rep. 2003; 4:36. [PubMed: 12537937]

2. Pantuck AJ, Zisman A, Belldegrun AS. The changing natural history of renal cell carcinoma. J Urol. 2001; 166:1611. [PubMed: 11586189]

3. Swanson DA. Surgery for metastases of renal cell carcinoma. Scand J Surg. 2004; 93:150. [PubMed: 15285568]

4. Karam JA, Rini BI, Varella L, et al. Metastasectomy after targeted therapy in patients with advanced renal cell carcinoma. J Urol. 2011; 185:439. [PubMed: 21167518]

5. Eggener SE, Yossepowitch O, Kundu S, et al. Risk score and metastasectomy independently impact prognosis of patients with recurrent renal cell carcinoma. J Urol. 2008; 180:873. [PubMed: 18635225]

6. Kim B, Louie AC. Surgical resection following interleukin 2 therapy for metastatic renal cell carcinoma prolongs remission. Arch Surg. 1992; 127:1343. [PubMed: 1444797]

7. Giuliani L, Giberti C, Martorana G, et al. Radical extensive surgery for renal cell carcinoma: longterm results and prognostic factors. J Urol. 1990; 143:468. [PubMed: 2304155]

8. Alt AL, Boorjian SA, Lohse CM, et al. Survival after complete surgical resection of multiple metastases from renal cell carcinoma. Cancer. 2011; 117:2873. [PubMed: 21692048]

9. van der Poel HG, Roukema JA, Horenblas S, et al. Metastasectomy in renal cell carcinoma: A multicenter retrospective analysis. Eur Urol. 1999; 35:197. [PubMed: 10072620] 
10. Kwak C, Park YH, Jeong CW, et al. Sarcomatoid differentiation as a prognostic factor for immunotherapy in metastatic renal cell carcinoma. J Surg Oncol. 2007; 95:317. [PubMed: 17066434]

11. Kavolius JP, Mastorakos DP, Pavlovich C, et al. Resection of metastatic renal cell carcinoma. J Clin Oncol. 1998; 16:2261. [PubMed: 9626229]

12. Kierney PC, van Heerden JA, Segura JW, et al. Surgeon's role in the management of solitary renal cell carcinoma metastases occurring subsequent to initial curative nephrectomy: an institutional review. Ann Surg Oncol. 1994; 1:345. [PubMed: 7850534]

13. Farrow GM, Harrison EG Jr, Utz DC. Sarcomas and sarcomatoid and mixed malignant tumors of the kidney in adults. 3. Cancer. 1968; 22:556. [PubMed: 4299778]

14. Sella A, Logothetis CJ, Ro JY, et al. Sarcomatoid renal cell carcinoma. A treatable entity. Cancer. 1987; 60:1313. [PubMed: 2441841]

15. Escudier B, Droz JP, Rolland F, et al. Doxorubicin and ifosfamide in patients with metastatic sarcomatoid renal cell carcinoma: a phase II study of the Genitourinary Group of the French Federation of Cancer Centers. J Urol. 2002; 168:959. [PubMed: 12187199]

16. Shuch B, Said J, La Rochelle JC, et al. Cytoreductive nephrectomy for kidney cancer with sarcomatoid histology--is up-front resection indicated and, if not, is it avoidable? J Urol. 2009; 182:2164. [PubMed: 19758641]

17. Shuch B, Said J, LaRochelle JC, et al. Histologic evaluation of metastases in renal cell carcinoma with sarcomatoid transformation and its implications for systemic therapy. Cancer. 2010; 116:616. [PubMed: 19998348]

18. Mian BM, Bhadkamkar N, Slaton JW, et al. Prognostic factors and survival of patients with sarcomatoid renal cell carcinoma. J Urol. 2002; 167:65. [PubMed: 11743277]

19. Haas NB, Lin X, Manola J, et al. A phase II trial of doxorubicin and gemcitabine in renal cell carcinoma with sarcomatoid features: ECOG 8802. Med Oncol. 2012; 29:761. [PubMed: 21298497]

20. Golshayan AR, George S, Heng DY, et al. Metastatic sarcomatoid renal cell carcinoma treated with vascular endothelial growth factor-targeted therapy. J Clin Oncol. 2009; 27:235. [PubMed: 19064974]

21. Edge, SB. American Joint Committee on Cancer. American Cancer Society.: AJCC cancer staging handbook : from the AJCC cancer staging manual. 7th. New York: Springer; 2010. p. xixp. 718

22. Ho DE, Imai K, King G, et al. Matching as nonparametric preprocessing for reducing model dependence in parametric causal inference. Political Analysis. 2007; 15:199.

23. Ho DE, Imai K, King G, et al. MatchIt: Nonparametric Preprocessing for Parametric Causal Inference. Journal of Statistical Software. 2007b; 42

24. Dabestani S, Marconi L, Hofmann F, et al. Local treatments for metastases of renal cell carcinoma: a systematic review. Lancet Oncol. 2014; 15:e549. [PubMed: 25439697]

25. Kwak C, Park YH, Jeong CW, et al. Metastasectomy without systemic therapy in metastatic renal cell carcinoma: comparison with conservative treatment. Urol Int. 2007; 79:145. [PubMed: 17851285]

26. Russo P. Surgical intervention in patients with metastatic renal cancer: current status of metastasectomy and cytoreductive nephrectomy. Nat Clin Pract Urol. 2004; 1:26. [PubMed: 16474463]

27. Thomas AZ, Adibi M, Borregales LD, et al. Surgical Management for Local Retroperitoneal Recurrence Of Renal Cell Carcinoma After Radical Nephrectomy. J Urol. 2015

28. Park I, Cho YM, Lee JL, et al. Prognostic factors of metastatic renal cell carcinoma with extensive sarcomatoid component. J Cancer Res Clin Oncol. 2013; 139:817. [PubMed: 23397357]

29. McKay RR, Kroeger N, Xie W, et al. Impact of Bone and Liver Metastases on Patients with Renal Cell Carcinoma Treated with Targeted Therapy. European Urology. 2014; 65:577. [PubMed: 23962746]

30. Naito S, Kinoshita H, Kondo T, et al. Prognostic factors of patients with metastatic renal cell carcinoma with removed metastases: a multicenter study of 556 patients. Urology. 2013; 82:846. [PubMed: 24074981] 


\section{Key of Abbreviations}

RN radical nephrectomy

SRCC sarcomatoid dedifferentiation

ECOG Eastern Cooperative Oncology Group

LN lymph node

CT computerized tomography

OS

Overall survival 


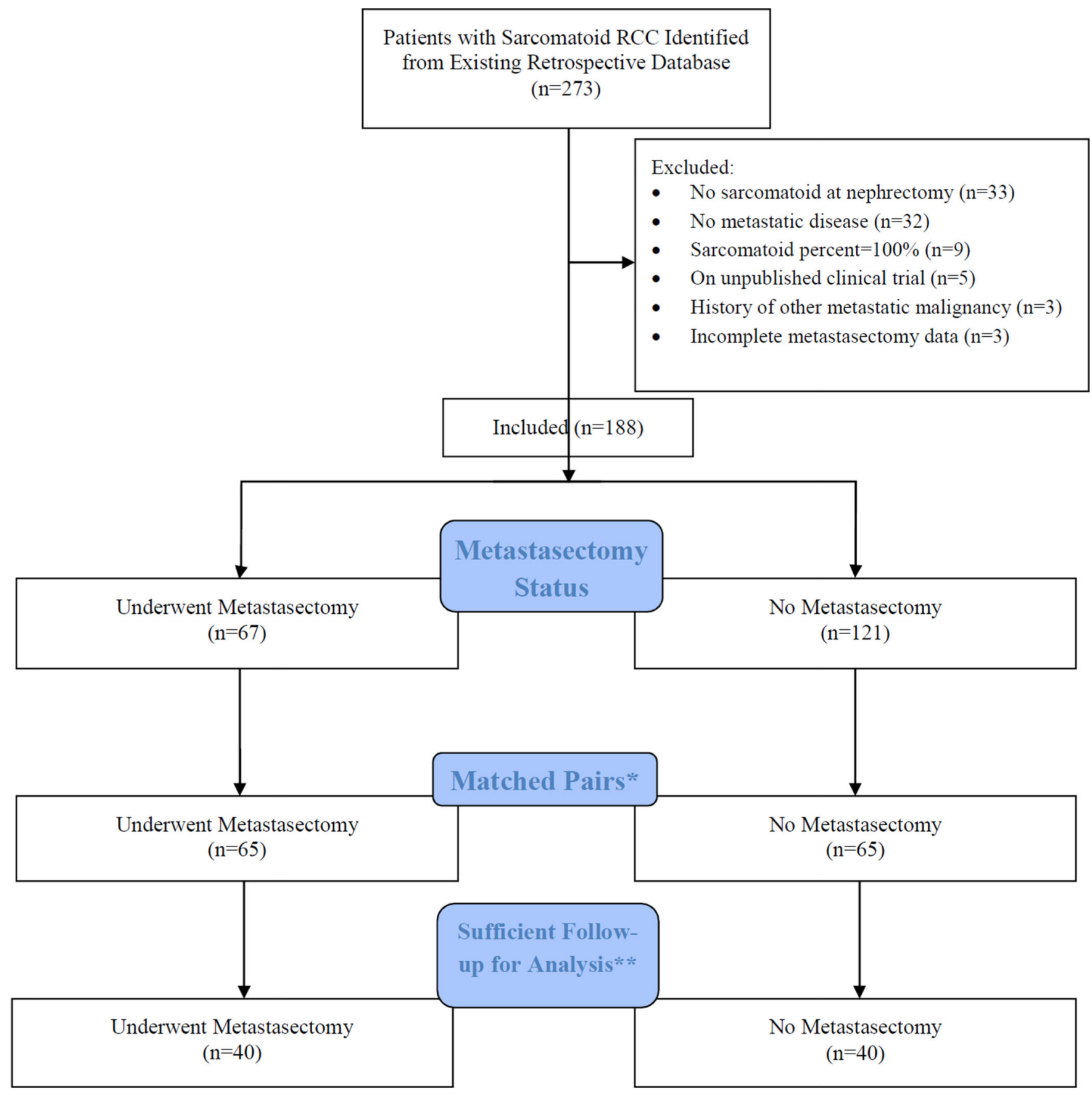

Figure 1.

Patient Inclusion Flow Diagram

*Patients with metastasectomy were matched to patients without based on ECOG performance status, age group ( 55 vs $>55$ years), histology, and pathological stage and nodal status at RN.

**For a pair to be included in analyses, patients without a metastasectomy had to live long enough to have received a metastasectomy at the same time as their pairmate. 


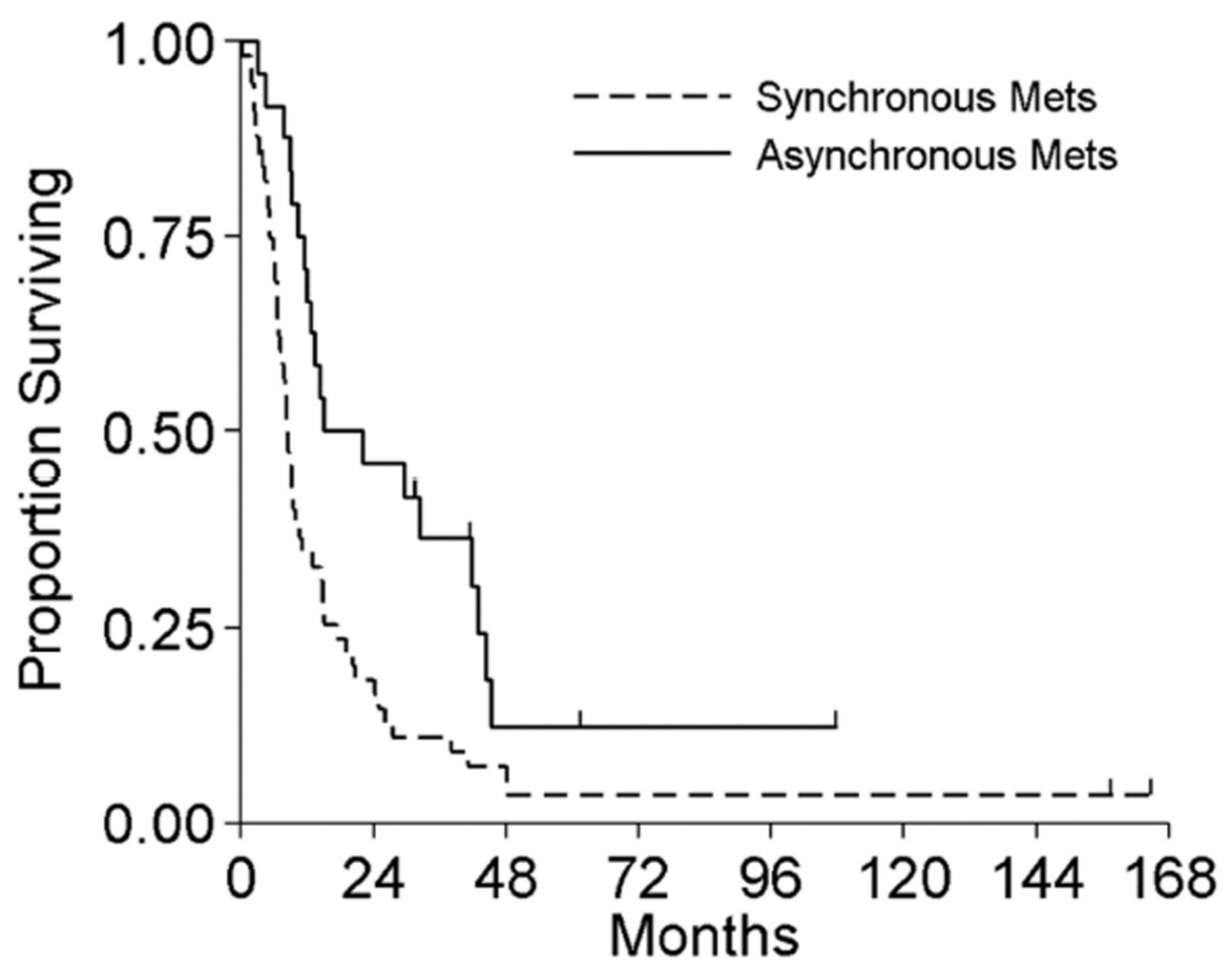

\section{Number at risk \\ $\begin{array}{llllllll}\text { Synchronous Mets } 56 & 10 & 3 & 2 & 2 & 2 & 2 & 0\end{array}$ $\begin{array}{llllllll}\text { Asynchronous Mets } 24 & 11 & 2 & 1 & 1 & 0 & 0 & 0\end{array}$}

Figure 2.

Overall Survival among All Metastatic Patients by Metastatic Synchronicity 
A.

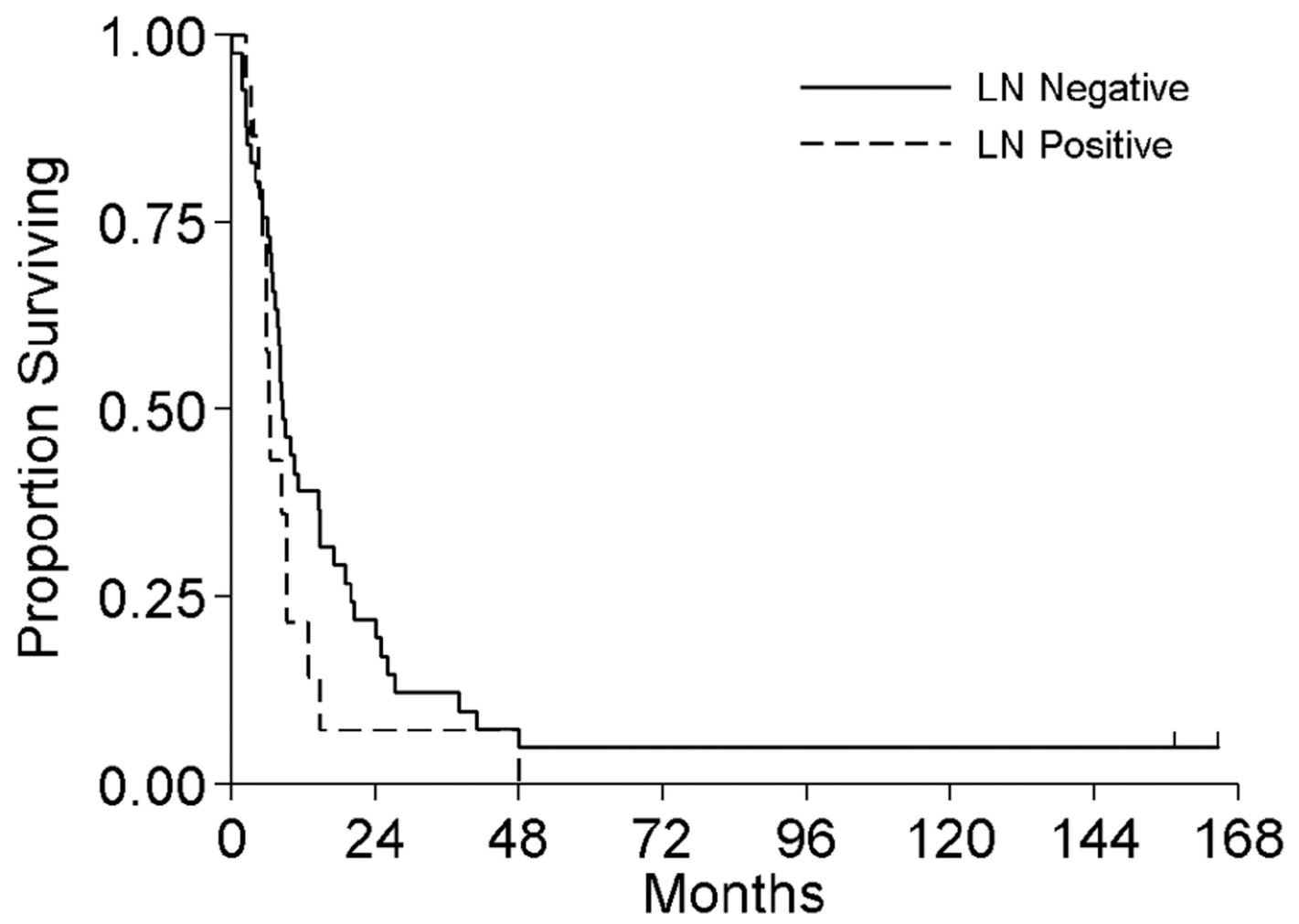

Number at risk

$\begin{array}{cccccccc}\text { LN Negative } 41 & 9 & 2 & 2 & 2 & 2 & 2 & 0 \\ \text { LN Positive } 15 & 1 & 1 & 0 & 0 & 0 & 0 & 0\end{array}$


B.

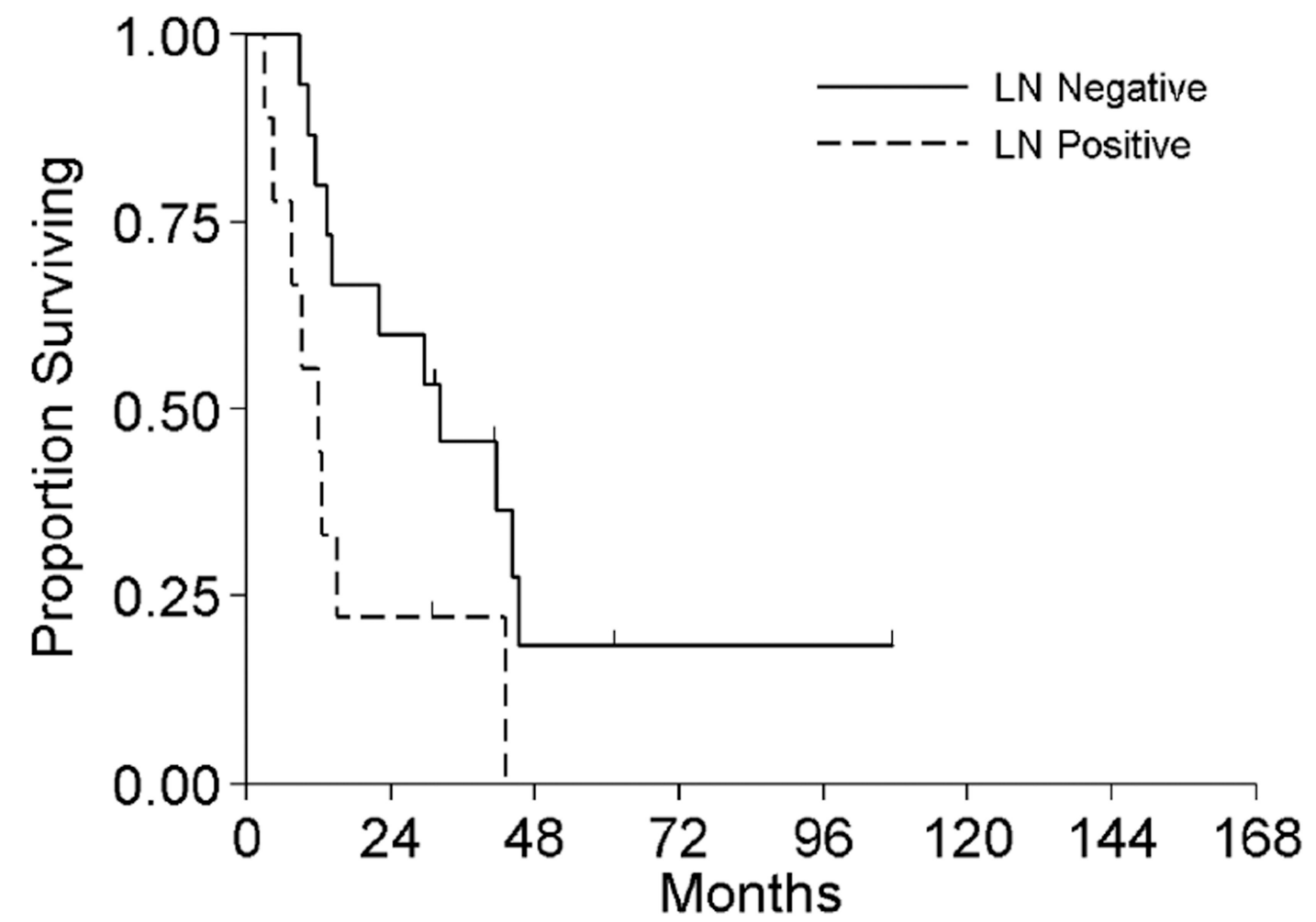

Number at risk

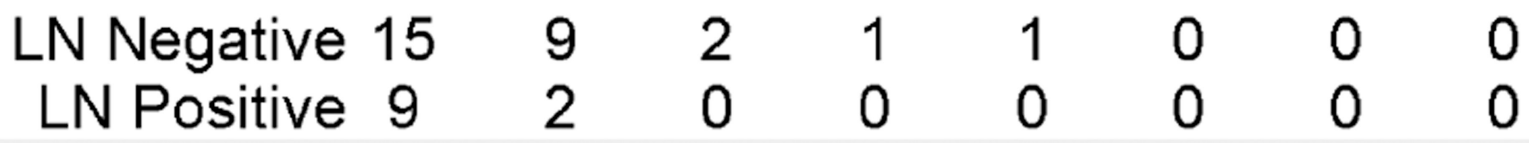

Figure 3.

A. Overall Survival by Lymph Node Status among Patients with Synchronous Metastases

B. Overall Survival by Lymph Node Status among Patients with Asynchronous Metastases 
A.

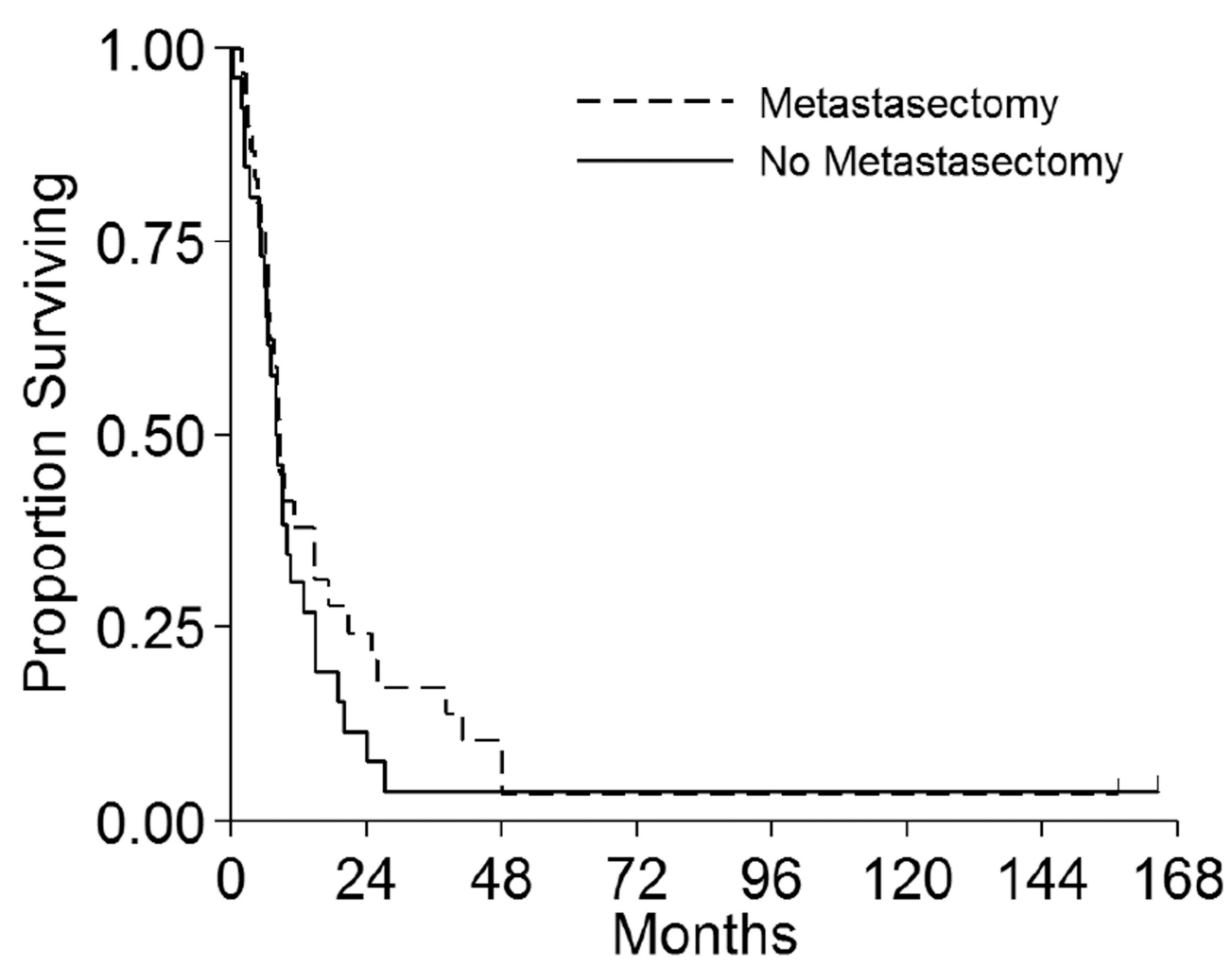

Number at risk

$\begin{array}{rrrrrrrr}\text { Metastasectomy } 30 & 7 & 2 & 1 & 1 & 1 & 1 & 0 \\ \text { No Metastasectomy 26 } & 3 & 1 & 1 & 1 & 1 & 1 & 0\end{array}$


B.

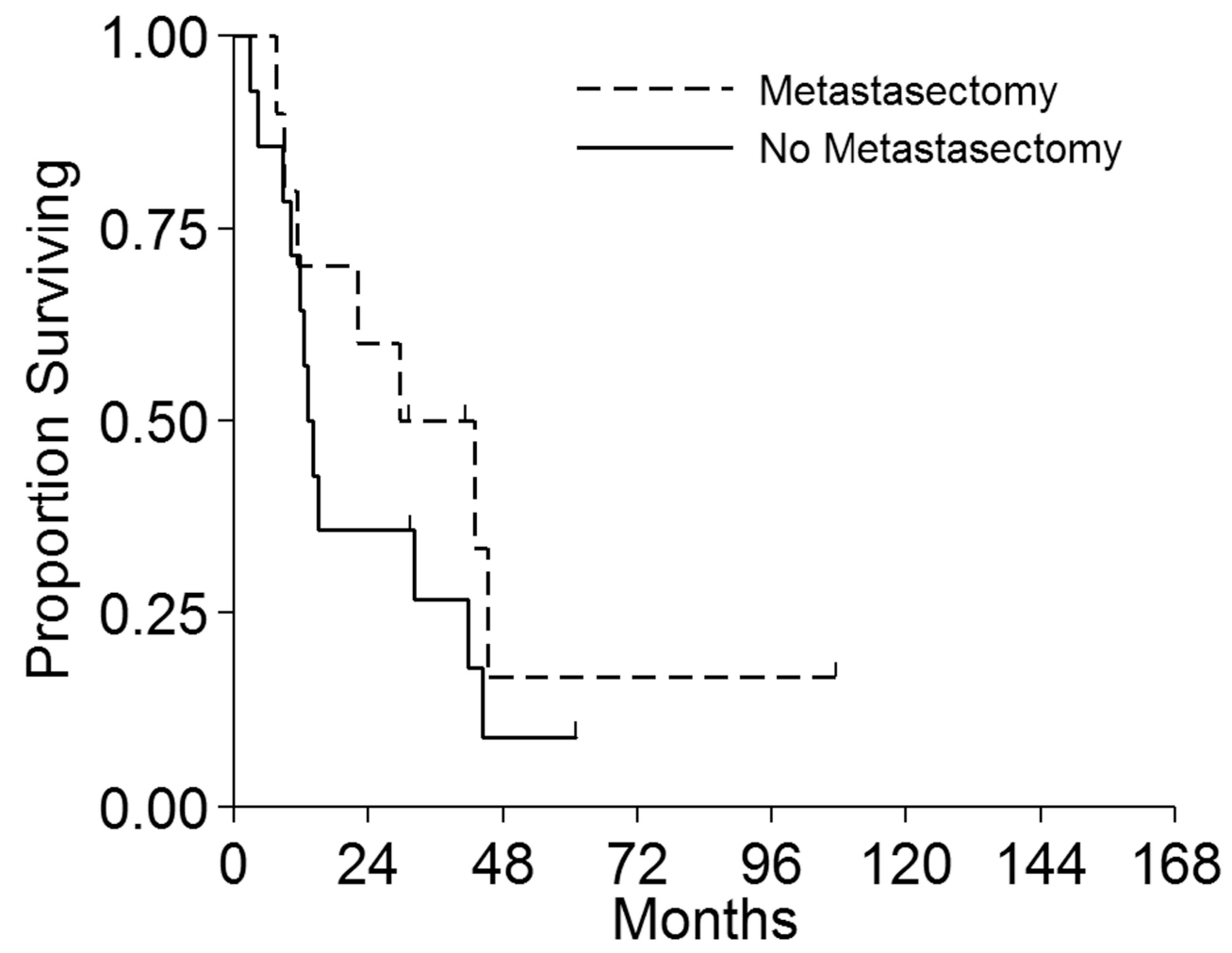

\section{Number at risk \\ $\begin{array}{llllllll}\text { Metastasectomy } 10 & 6 & 1 & 1 & 1 & 0 & 0 & 0\end{array}$

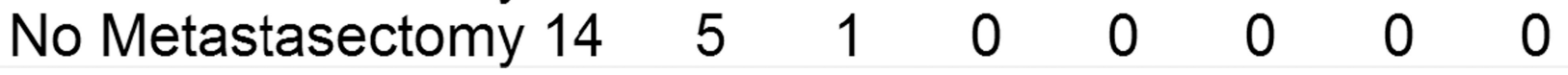 \\ Figure 4. \\ A. Overall Survival by Metastasectomy among Patients with Synchronous Metastases \\ B. Overall Survival by Metastasectomy among Patients with Asynchronous Metastases}




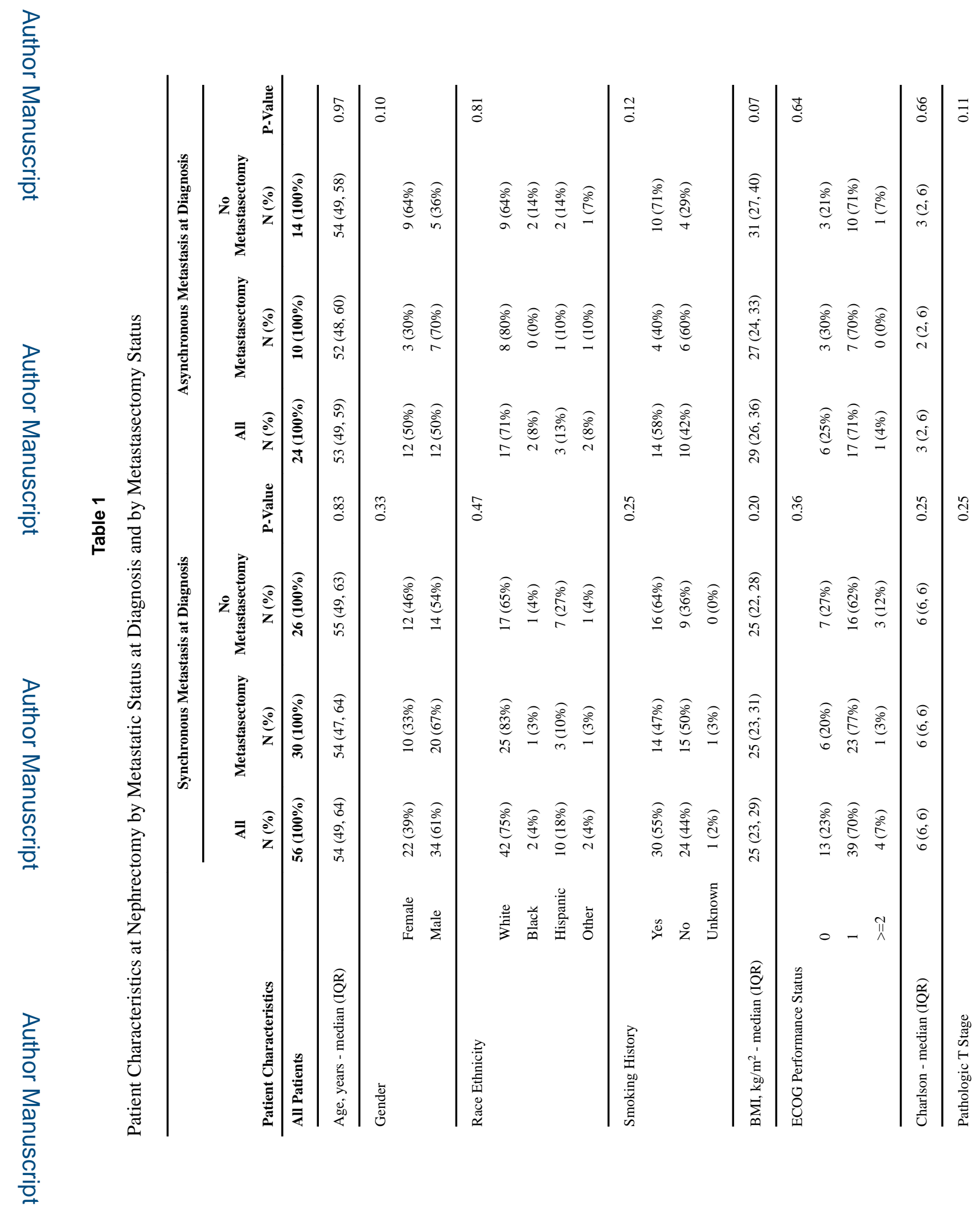

J Urol. Author manuscript; available in PMC 2017 September 01. 


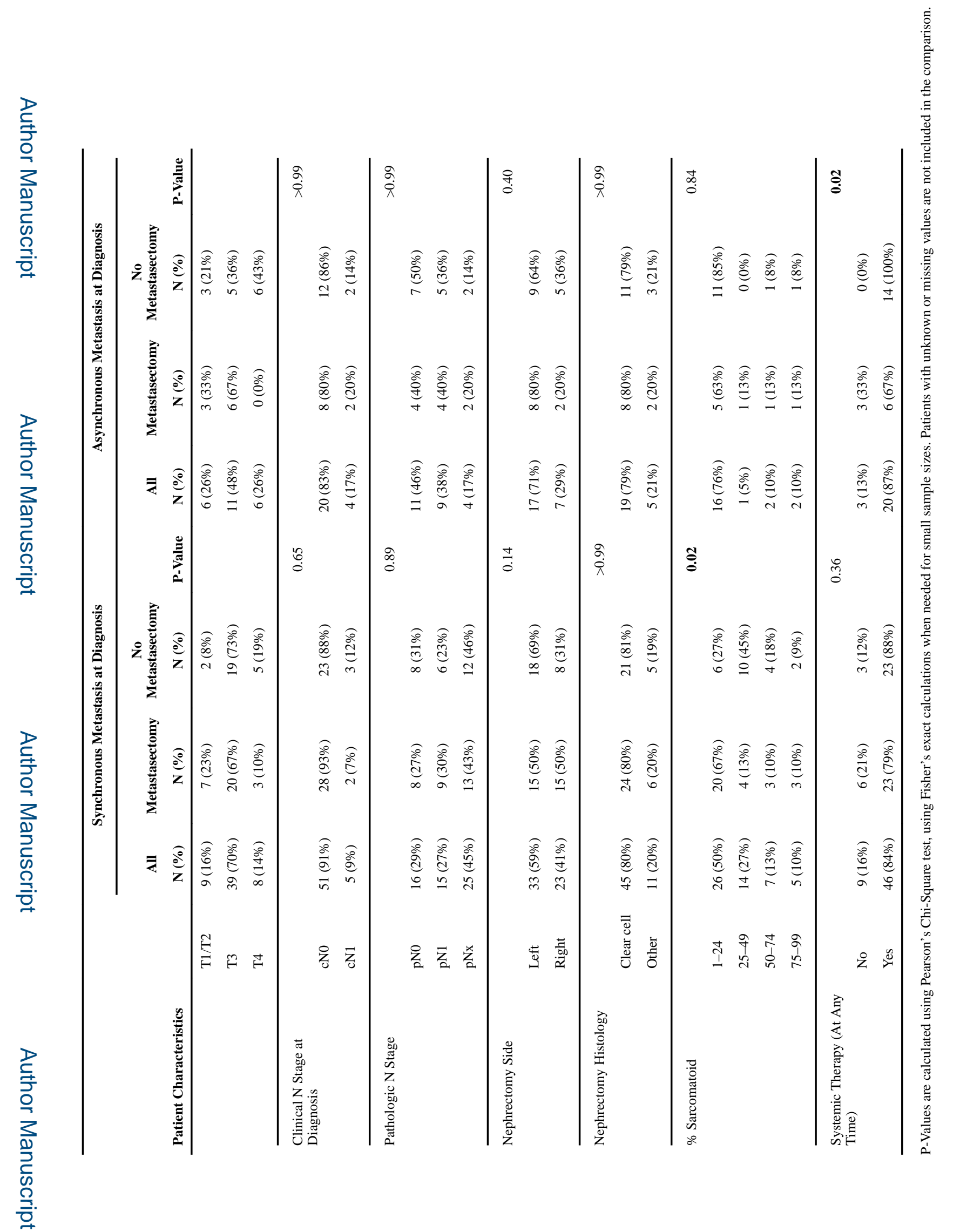

J Urol. Author manuscript; available in PMC 2017 September 01. 
Table 2

Synchronous Metastatic Sites at Diagnosis by Metastasectomy Status and Disease Status after Nephrectomy

\begin{tabular}{lcccc}
\hline & All & Metastasectomy & $\begin{array}{c}\text { No } \\
\text { Metastasectomy }\end{array}$ & \\
Metastatic Site & $\mathbf{N}(\boldsymbol{\%})$ & $\mathbf{N}(\boldsymbol{\%})$ & $\mathbf{N}(\mathbf{\% )}$ & P-Value \\
\hline All Patients & $\mathbf{5 6 ( 1 0 0 \% )}$ & $\mathbf{3 0}(\mathbf{1 0 0 \%})$ & $\mathbf{2 6}(\mathbf{1 0 0 \% )}$ & \\
\hline Brain & $5(9 \%)$ & $4(13 \%)$ & $1(4 \%)$ & 0.36 \\
Lung & $35(63 \%)$ & $18(60 \%)$ & $17(65 \%)$ & 0.68 \\
Mediastinum & $3(5 \%)$ & $2(7 \%)$ & $1(4 \%)$ & $>0.99$ \\
Liver & $5(9 \%)$ & $1(3 \%)$ & $4(15 \%)$ & 0.17 \\
Pancreas & $3(5 \%)$ & $2(7 \%)$ & $1(4 \%)$ & $>0.99$ \\
Bone & $25(45 \%)$ & $17(57 \%)$ & $8(31 \%)$ & 0.052 \\
Spleen & $3(5 \%)$ & $1(3 \%)$ & $2(8 \%)$ & 0.59 \\
Soft Tissue & $4(7 \%)$ & $1(3 \%)$ & $3(12 \%)$ & 0.33 \\
Supraclavicular LN & $1(2 \%)$ & $0(0 \%)$ & $1(4 \%)$ & 0.46 \\
Adrenal gland & $2(4 \%)$ & $1(3 \%)$ & $1(4 \%)$ & $>0.99$ \\
\hline
\end{tabular}


Table 3

Asynchronous Metastatic Sites after Diagnosis * by Metastasectomy Status

\begin{tabular}{|c|c|c|c|c|}
\hline Metastatic Site & $\begin{array}{c}\text { All } \\
\mathbf{N}(\%)\end{array}$ & $\begin{array}{c}\text { Metastasectomy } \\
\text { N (\%) }\end{array}$ & $\begin{array}{c}\text { No } \\
\text { Metastasectomy } \\
\text { N (\%) }\end{array}$ & P-Value \\
\hline All Patients & $24(100 \%)$ & $10(100 \%)$ & $14(100 \%)$ & \\
\hline Brain & $5(21 \%)$ & $5(50 \%)$ & $0(0 \%)$ & 0.01 \\
\hline Lung & $12(50 \%)$ & $3(30 \%)$ & $9(64 \%)$ & 0.10 \\
\hline Mediastinum & $1(4 \%)$ & $0(0 \%)$ & $1(7 \%)$ & $>0.99$ \\
\hline Liver & $4(17 \%)$ & $1(10 \%)$ & $3(21 \%)$ & 0.61 \\
\hline Bone & $2(8 \%)$ & $2(20 \%)$ & $0(0 \%)$ & 0.08 \\
\hline Soft Tissue & $3(13 \%)$ & $2(20 \%)$ & $1(7 \%)$ & 0.55 \\
\hline Adrenal gland & $2(4 \%)$ & $1(3 \%)$ & $1(4 \%)$ & $>0.99$ \\
\hline Retroperitoneal LN & $1(2 \%)$ & $0(0 \%)$ & $1(4 \%)$ & 0.46 \\
\hline
\end{tabular}

These sites are provided for the 24 patients with no distant metastases at diagnosis. 
Table 4

Patient Metastasectomy Characteristics for the 40 Patients Undergoing at Least One Metastasectomy

\begin{tabular}{|c|c|c|c|}
\hline Patient Characteristics & & $\begin{array}{c}\text { Synchronous } \\
\text { Group } \\
\text { Metastasectomy } \\
\mathbf{N}(\%)\end{array}$ & $\begin{array}{c}\text { Asynchronous Group } \\
\text { Metastasectomy } \\
\text { N (\%) }\end{array}$ \\
\hline Any Metastasectomy & & $30(100 \%)$ & $10(100 \%)$ \\
\hline \multicolumn{4}{|l|}{ Organ Site } \\
\hline & Bone & $17(57 \%)$ & $1(10 \%)$ \\
\hline & Brain & $9(30 \%)$ & $5(50 \%)$ \\
\hline & Lung & $2(7 \%)$ & $2(20 \%)$ \\
\hline & Intraabdominal & $1(3 \%)$ & $2(20 \%)$ \\
\hline & Other & $1(3 \%)$ & $0(0 \%)$ \\
\hline \multicolumn{4}{|c|}{ Number of Sites at $1^{\text {st }}$ Metastasectomy* } \\
\hline & 1 & $27(93 \%)$ & $10(100 \%)$ \\
\hline & $>1$ & $2(7 \%)$ & $0(0 \%)$ \\
\hline \multicolumn{4}{|c|}{ Number of Metastasectomy Sessions } \\
\hline & 1 & $19(63 \%)$ & $5(50 \%)$ \\
\hline & 2 & $5(17 \%)$ & $2(20 \%)$ \\
\hline & 3 or 4 & $6(20 \%)$ & $3(30 \%)$ \\
\hline
\end{tabular}




\section{를}

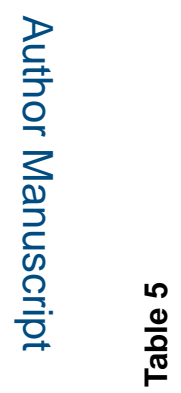

\}

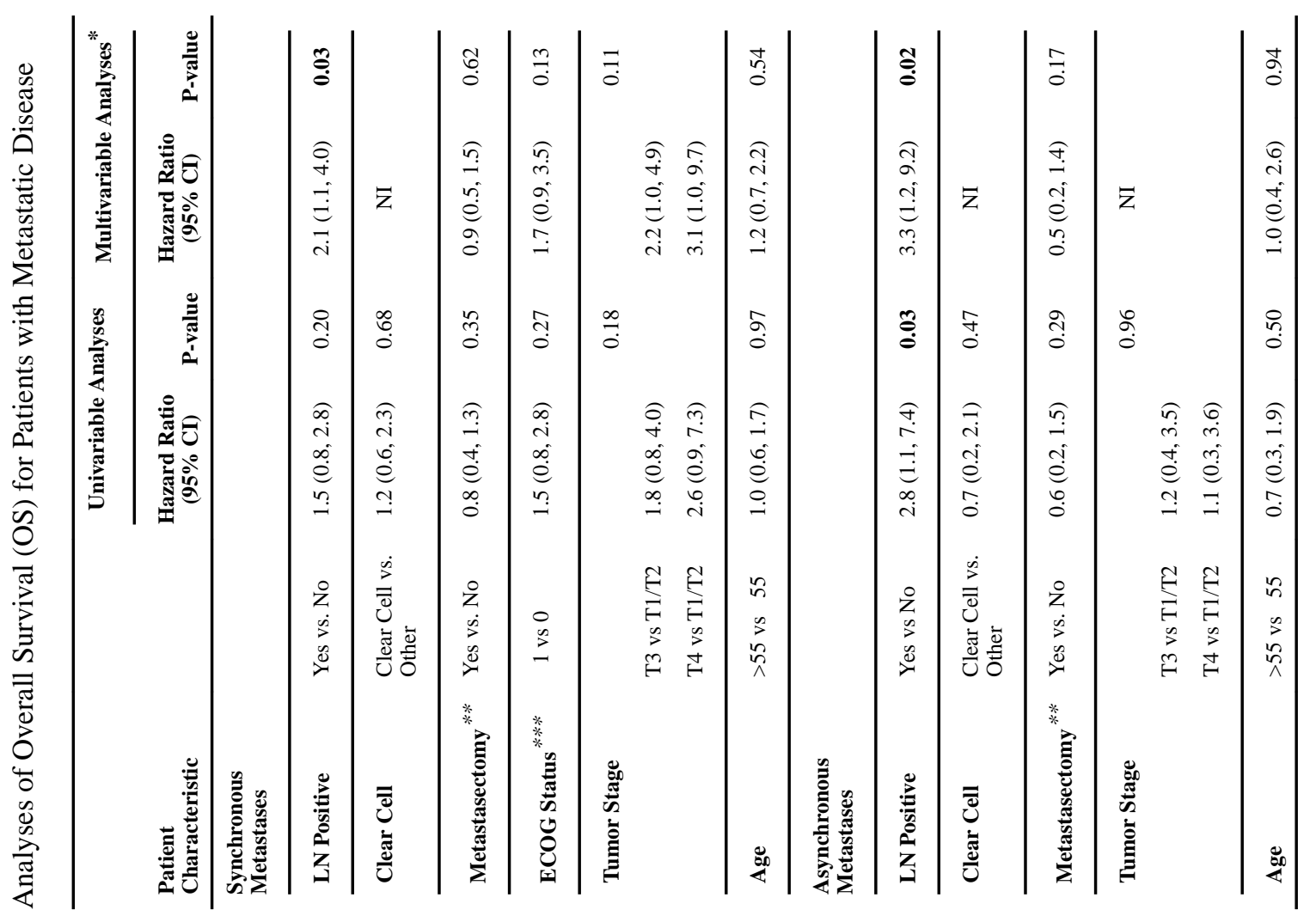

J Urol. Author manuscript; available in PMC 2017 September 01. 


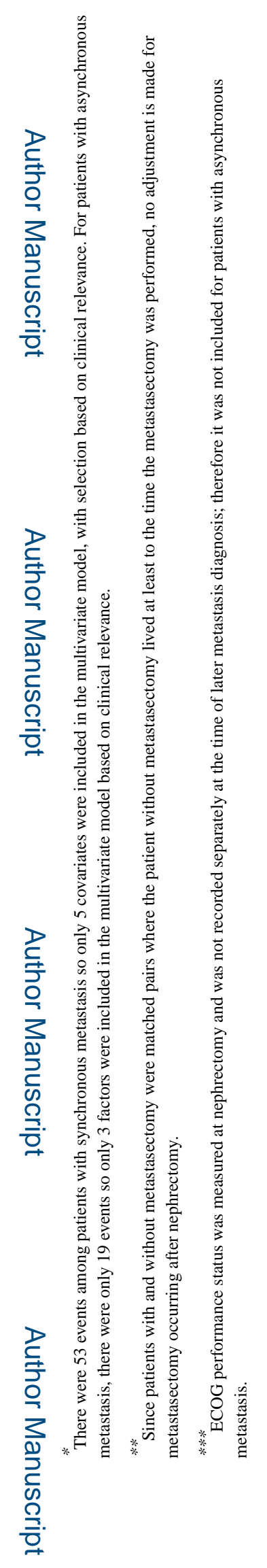

J Urol. Author manuscript; available in PMC 2017 September 01. 